\title{
Facile Synthesis of Dendritic-Linear-Dendritic Materials by Click Chemistry
}

\author{
Jae Wook Lee*, Seung Choul Han, Byoung-Ki Kim, Un Yup Lee, Sae Reum Sung, and Hwa-Shin Kang \\ Department of Chemistry and Department of Medical Bioscience, Dong-A University, Busan 604-714, Korea
}

\author{
Ji Hyeon Kim
}

Department of Chemical and Bio Engineering, Kyungwon University, Seongnam 461-701, Korea

\author{
Sung-Ho Jin
}

Department of Chemistry Education \& Center for Plastic Information System, Pusan National University, Busan 609-735, Korea

Received October 4, 2008; Revised November 5, 2008; Accepted November 29, 2008

\begin{abstract}
General, fast, and efficient stitching methods are presented for the synthesis of Fréchet-type dendrimers with linear units at a core, as a preliminary investigation for the synthesis of dendritic-linear-dendritic materials. The synthetic strategy involved an inexpensive, 1,3-dipolar, cycloaddition reaction between an alkyne and an azide in the presence of the $\mathrm{Cu}(\mathrm{I})$ species, which is known as the best example of click chemistry. The linear core building blocks, 1,7-octadiyne and 1,6-diazidohexane, were chosen to serve as the alkyne and azide functionalities for dendrimer growth via click reactions with the azide and alkyne-dendrons, respectively. These two building blocks were employed together with the azide- and alkyne-functionalized Fréchet-type dendrons in a convergent strategy to synthesize two kinds of Fréchet-type dendrimers with different linear core units. This comparative efficiency of the click methodology supports the fast and efficient synthesis of dendritic-linear-dendritic materials with the tailor made core unit.
\end{abstract}

Keywords: alkyne, azide, click chemistry, dendritic-linear-dendritic materials, Fréchet-type dendrimers.

\section{Introduction}

Dendrons and dendrimers are the most intensely investigated subset of dendritic polymers. Dendrimers, which are prepared by repetition of a given set of reactions using either divergent or convergent strategies, are highly branched and regular macromolecules with well-defined structures and have served as functional objects in nanotechnology and nanoscience. ${ }^{1,2}$ The amphiphilic dendrimer polymers consisting of both hydrophobic and hydrophilic regions in the same molecule appear as an important issue throughout the physical and life sciences and can be considered unimolecular micelles. Amphiphilic dendrimer polymers can be classified into dendritic-linear polymers possessing a hydrophilic dendritic component and a hydrophobic linear polymer (or vice versa) and unimolecular dendritic amphiphiles. ${ }^{3}$ Amphiphilic dendritic-linear block copolymers are believed to combine the advantageous properties of both linear and dendritic amphiphiles. ${ }^{4-8}$ Dendritic-linear diblock copolymers have been synthesized by the stepwise preparation methods, which proceed in either a convergent or divergent strategy.

*Corresponding Author. E-mail: jlee@donga.ac.kr
The former involves the coupling of preformed linear polymers functionalized at one or both chain ends with reactive dendrons having a complementary functionality at their focal point. ${ }^{9-12}$ The latter is that the dendritic segment is grown via a divergent strategy from a suitably end-functionalized linear polymer ${ }^{13-15}$ or that reactive functionality at the focal point of dendrons can also serve as macromolecular initiators in the polymerization. ${ }^{16}$

The building blocks of the linear-dendritic copolymers are only two, but they could be positioned in several distinct configurations due to the presence of multiple anchoring points in both of them. The size (length and generation) and the polarity of the blocks would determine the relative hydrophobic/hydrophilic balance and ultimately affect the solution and solid-state properties of the hybrids. The characteristic feature is the attachment of two monodendrons to the extremities of a single linear chain. The variation of chain length and dendrimer size in this group also offers interesting macromolecular geometries. ${ }^{17}$ The reaction, which leads to quantitative formation of linear-dendritic structures, is the Williamson ether synthesis involving aliphatic primary alcohols and benzyl bromide-containing monodendrons. ${ }^{11}$ However, it should be noted that the attempted 


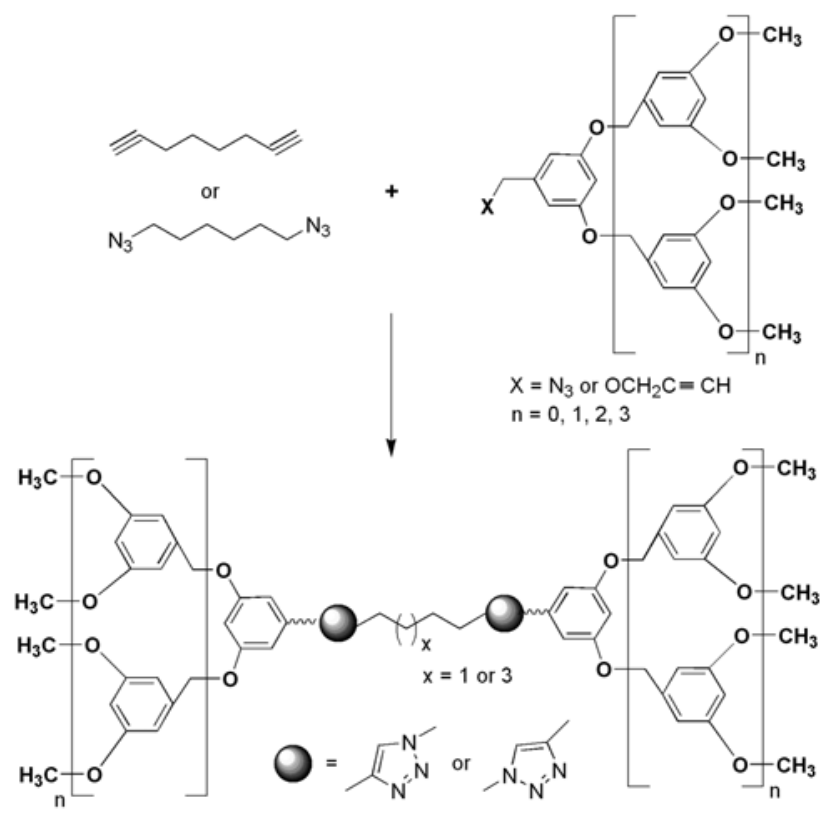

Figure 1. Structures of dendrons and synthetic strategy of dendrimers.

Williamson ether reaction between Fréchet-type dendritic bromides and hydroxyl-terminated poly(styrene) homopolymer or poly(styrene)-block-poly(ethylene oxide) copolymer failed to produce the desired linear-dendritic structure. ${ }^{18}$ Probably the block solubility and compatibility is the dominant (and prohibitive) factor in this case since the reactivity of both participating groups should remain the same as in the previous studies. The coupling chemistry has a similar effect on the outcome of the synthesis. Recent solid chemistry is the click chemistry which is the copper-catalyzed 1,3dipolar cycloaddition reaction between alkyne and azide developed by Sharpless and Tornøe. ${ }^{19}$ This reaction is characterized by mild and simple reaction conditions, reliable 1,4-regiospecific 1,2,3-triazole formations, and tolerance towards water as well as a wide range of functionalities, and is clearly a breakthrough in the synthesis of dendrimers ${ }^{20,21}$ and dendritic and polymer materials. ${ }^{22-24}$ We have developed the fusion and stitching methods for the synthesis of dendrimers and diblock codendrimers using click chemistry between an alkyne and an azide. ${ }^{21}$ Taking advantage of this fact, herein we report the synthesis of Fréchet-type dendrimers with linear core moieties by the stitching method of dendrons (Figure 1). Because of the high yields and lack of byproducts provided by the click chemistry for stitching together dendrons and core unit, the various dendritic-linear-dendritic materials could be obtained easily and shown the characteristic behaviors.

\section{Experimental}

General. ${ }^{1} \mathrm{H}$ NMR spectra were recorded on a 300 or
$500 \mathrm{MHz}$ NMR spectrometer using the residual proton resonance of the solvent as the internal standard. Chemical shifts are reported in parts per million (ppm). When peak multiplicities are given, the following abbreviations are used: s, singlet; d, doublet; t, triplet; q, quartet; quin, quintet; $\mathrm{d}$ of $\mathrm{d}$, doublet of a doublet; $\mathrm{m}$, multiplet; br, broad. ${ }^{13} \mathrm{C}$ NMR spectra were proton decoupled and recorded on a 75 or $125 \mathrm{MHz}$ NMR spectrometer using the carbon signal of the deuterated solvent as the internal standard. FAB and MALDI mass spectra were obtained from Korea Basic Science Institute (KBSI) in Daegu or Daejeon and POSTECH. Flash chromatography was performed with $37-75 \mu \mathrm{m}$ silica gel. Analytical thin layer chromatography was performed on silica plates with $\mathrm{F}_{254}$ indicator and the visualization was accomplished by UV lamp or using an iodine chamber. Polydispersity (PDI) of dendrimers was determined by gel permeation chromatography (GPC) analysis relative to polystyrene calibration (Agilent 1100 series GPC, Plgel $5 \mu \mathrm{m}$ MIXED-C, refractive index detector) in THF solution.

General Procedure for the Preparation of Dendrimers 5-Gm from Azide-dendrons 1-Dm and 1,7-Octadiyne 3. A mixture of azido-dendrons 1-Dm $(0.22 \mathrm{mmol})$ and 1,7octadiyne $3(0.1 \mathrm{mmol})$ in $\mathrm{DMF}_{-} \mathrm{H}_{2} \mathrm{O}(4: 1,2 \mathrm{~mL})$ in the presence of $10 \mathrm{~mol}^{\%} \mathrm{CuSO}_{4} \cdot 5 \mathrm{H}_{2} \mathrm{O}$ with $20 \mathrm{~mol} \%$ sodium ascorbate was stirred at $50^{\circ} \mathrm{C}$ for $\sim 18 \mathrm{~h}$. The reaction mixture was poured into brine $(20 \mathrm{~mL})$ and the resulting solution was extracted with EtOAc $(20 \mathrm{~mL} \times 3)$. The combined organic phase was dried with sodium sulfate, concentrated, and purified by column chromatography to afford the desired product 5-Gm.

5-G1. A yellowish oil; 98\% yield; IR 3009, 2940, 2839, 1597, 1466, 1350, 1204, 1157, $1057 \mathrm{~cm}^{-1}$; ${ }^{1} \mathrm{H}$ NMR (300 $\left.\mathrm{MHz}, \mathrm{CDCl}_{3}\right) \delta 1.69(\mathrm{t}, J=3.3 \mathrm{~Hz}, 4 \mathrm{H}), 2.68(\mathrm{~m}, 4 \mathrm{H}), 3.72$ (s, 12H), $5.36(\mathrm{~s}, 4 \mathrm{H}), 6.35(\mathrm{~d}, J=1.9 \mathrm{~Hz}, 4 \mathrm{H}), 6.38$ (t, $J=$ $2.0 \mathrm{~Hz}, 2 \mathrm{H}), 7.19(\mathrm{~s}, 2 \mathrm{H}) ;{ }^{13} \mathrm{C} \mathrm{NMR}\left(75 \mathrm{MHz}, \mathrm{CDCl}_{3}\right)$ $\delta 25.4,28.8,54.0,55.3,100.3,105.9,120.6,137.0,148.4$, 161.2; MS (FAB): $m / z$ 493.2 [M ${ }^{+}+\mathrm{H}$ ]; HRMS (FAB) Calcd for $\mathrm{C}_{26} \mathrm{H}_{32} \mathrm{~N}_{6} \mathrm{O}_{4}: 492.2485$. Found: $493.2564\left[\mathrm{M}^{+}+\mathrm{H}\right]$. PDI: 1.01 .

5-G2. A yellowish oil; 97\% yield; IR 3009, 2940, 2839, 1597, 1458, 1350, 1204, 1150, $1049 \mathrm{~cm}^{-1}$; ${ }^{1} \mathrm{H}$ NMR (300 $\left.\mathrm{MHz}, \mathrm{CDCl}_{3}\right) \delta 1.72(\mathrm{~m}, 4 \mathrm{H}), 2.71(\mathrm{~m}, 4 \mathrm{H}), 3.78(\mathrm{~s}, 24 \mathrm{H})$, $4.91(\mathrm{~s}, 8 \mathrm{H}), 5.36(\mathrm{~s}, 4 \mathrm{H}), 6.40(\mathrm{t}, J=2.0 \mathrm{~Hz}, 4 \mathrm{H}), 6.45$ (d, $J=1.8 \mathrm{~Hz}, 4 \mathrm{H}), 6.53$ (d, $J=2.0 \mathrm{~Hz}, 8 \mathrm{H}), 6.55(\mathrm{~m}, 2 \mathrm{H}), 7.17$ $(\mathrm{s}, 2 \mathrm{H}) ;{ }^{13} \mathrm{C} \mathrm{NMR}\left(75 \mathrm{MHz}, \mathrm{CDCl}_{3}\right) \mathrm{d} 25.3,28.8,53.9,55.3$, 70.0, 99.9, 102.0, 105.2, 107.1, 120.6, 137.1, 138.8, 148.4, 160.2, 161.0; MS (FAB): $m / z$ 1037.34 [M+ $+\mathrm{H}]$; HRMS (FAB) Calcd for $\mathrm{C}_{58} \mathrm{H}_{64} \mathrm{~N}_{6} \mathrm{O}_{12}: 1036.4582$. Found: $1037.4655\left[\mathrm{M}^{+}+\right.$ H]. PDI: 1.01 .

5-G3. A yellowish oil; 96\% yield; IR 3009, 2940, 2839, 1597, 1458, 1373, 1204, 1150, $1049 \mathrm{~cm}^{-1}$; ${ }^{1} \mathrm{H}$ NMR (500 $\left.\mathrm{MHz}, \mathrm{CDCl}_{3}\right) \delta 1.71(\mathrm{~m}, 4 \mathrm{H}), 2.70(\mathrm{~m}, 4 \mathrm{H}), 3.77(\mathrm{~s}, 48 \mathrm{H})$, $4.90(\mathrm{~s}, 8 \mathrm{H}), 4.95(\mathrm{~s}, 16 \mathrm{H}), 5.34(\mathrm{~s}, 4 \mathrm{H}), 6.41(\mathrm{~m}, 8 \mathrm{H}), 6.44$ (m, 4H), 6.54-6.57 (m, 22H), $6.64(\mathrm{~m}, 8 \mathrm{H}), 7.19(\mathrm{~s}, 2 \mathrm{H})$; 
${ }^{13} \mathrm{C}-\mathrm{NMR}\left(75 \mathrm{MHz}, \mathrm{CDCl}_{3}\right) \delta 25.2,28.7,53.7,55.2,69.9$, 99.7, 101.5, 101.8, 105.1, 106.2, 106.9, 120.6, 137.1, 138.8, 139.00, 148.3, 159.9, 160.1, 160.9; MS (FAB): $m / z 2127.1$ $\left[\mathrm{M}^{+}+3\right]$; HRMS (FAB) Calcd for $\mathrm{C}_{122} \mathrm{H}_{128} \mathrm{~N}_{6} \mathrm{O}_{28}: 2124.8777$. Found: $2125.8845\left[\mathrm{M}^{+}+\mathrm{H}\right]$. PDI: 1.01 .

5-G4. A yellowish oil; 94\% yield; IR 3009, 2940, 2839, 1597, 1458, 1373, 1204, 1150, $1049 \mathrm{~cm}^{-1}$; ${ }^{1} \mathrm{H}$ NMR (500 $\left.\mathrm{MHz}, \mathrm{CDCl}_{3}\right) \delta 1.74(\mathrm{~m}, 4 \mathrm{H}), 2.67(\mathrm{~m}, 4 \mathrm{H}), 3.75(\mathrm{~s}, 96 \mathrm{H})$, $4.87(\mathrm{~s}, 8 \mathrm{H}), 4.93(\mathrm{~s}, 48 \mathrm{H}), 5.29(\mathrm{~s}, 4 \mathrm{H}), 6.39(\mathrm{~m}, 16 \mathrm{H}), 6.43$ $(\mathrm{m}, 4 \mathrm{H}), 6.55(\mathrm{~m}, 46 \mathrm{H}), 6.62(\mathrm{~m}, 8 \mathrm{H}), 6.66(\mathrm{~m}, 16 \mathrm{H}), 7.15$ $(\mathrm{s}, 2 \mathrm{H}) ;{ }^{13} \mathrm{C} \mathrm{NMR}\left(75 \mathrm{MHz}, \mathrm{CDCl}_{3}\right) \delta 25.3,28.7,53.8,55.2$, 70.0, 99.8, 101.5, 101.8, 105.2, 106.4, 107.0, 120.7, 137.2, 138.9, 139.08, 139.14, 148.3, 160.0, 160.2, 160.9; MS (MALDI): Calcd for $\mathrm{C}_{250} \mathrm{H}_{256} \mathrm{~N}_{6} \mathrm{O}_{60}$ : 4301.7165. Found: $4325.4594\left[\mathrm{M}^{+}+\mathrm{Na}\right]$. PDI: 1.02 .

General Procedure for the Preparation of Dendrimers 6-Gm from Alkyne-dendrons 2-Dm and 1,6-Diazidohexane 4. A mixture of alkyne-dendrons 2-Dm (0.22 mmol) and 1,6-diazidohexane $4(0.1 \mathrm{mmol})$ in $\mathrm{DMF}_{2} \mathrm{H}_{2} \mathrm{O}(4: 1,2$ $\mathrm{mL}$ ) in the presence of $10 \mathrm{~mol} \% \mathrm{CuSO}_{4} \cdot 5 \mathrm{H}_{2} \mathrm{O}$ with $20 \mathrm{~mol} \%$ sodium ascorbate was stirred at $50{ }^{\circ} \mathrm{C}$ for $\sim 4.5 \mathrm{~h}$. The reaction mixture was poured into brine $(20 \mathrm{~mL})$ and the resulting solution was extracted with EtOAc $(20 \mathrm{~mL} \times 3)$. The combined organic phase was dried with sodium sulfate, concentrated, and purified by column chromatography to afford the desired product 6-Gm.

6-G1. A yellowish oil; 98\% yield; IR 3017, 2940, 2839, 1597, 1458, 1204, 1150, $1049 \mathrm{~cm}^{-1}$; ${ }^{1} \mathrm{H}$ NMR $(500 \mathrm{MHz}$, $\left.\mathrm{CDCl}_{3}\right) \delta 1.35$ (quin, $J=7.1 \mathrm{~Hz}, 4 \mathrm{H}$ ), $1.89(\mathrm{t}, J=6.8 \mathrm{~Hz}$, $4 \mathrm{H}), 3.87(\mathrm{~s}, 12 \mathrm{H}), 4.32(\mathrm{t}, J=7.1 \mathrm{~Hz}, 4 \mathrm{H}), 4.54(\mathrm{~s}, 4 \mathrm{H})$, $4.67(\mathrm{~s}, 4 \mathrm{H}), 6.38(\mathrm{t}, J=2.2 \mathrm{~Hz}, 2 \mathrm{H}), 6.51(\mathrm{t}, J=2.1 \mathrm{~Hz}$, $4 \mathrm{H}), 7.51(\mathrm{~s}, 2 \mathrm{H}) ;{ }^{13} \mathrm{C} \mathrm{NMR}\left(75 \mathrm{MHz}, \mathrm{CDCl}_{3}\right) \delta 25.8,29.9$, 50.0, 55.3, 63.6, 72.5, 99.7, 105.5, 122.3, 140.2, 145.1, 160.8; MS (FAB): $m / z 581.47\left[\mathrm{M}^{+}+\mathrm{H}\right]$; HRMS (FAB) Calcd for $\mathrm{C}_{30} \mathrm{H}_{40} \mathrm{~N}_{6} \mathrm{O}_{6}$ : 580.3009. Found: $581.3085\left[\mathrm{M}^{+}+\right.$ H]. PDI: 1.01 .

6-G2. A yellowish oil; 95\% yield; IR 3009, 2940, 2847, 1597, 1450, 1204, 1150, $1042 \mathrm{~cm}^{-1}$; ${ }^{1} \mathrm{H}$ NMR (500 MHz, $\left.\mathrm{CDCl}_{3}\right) \delta 1.34(\mathrm{~m}, 4 \mathrm{H}), 1.88(\mathrm{t}, J=6.4 \mathrm{~Hz}, 4 \mathrm{H}), 3.78(\mathrm{~s}$, $24 \mathrm{H}), 4.30(\mathrm{t}, J=7.0 \mathrm{~Hz}, 4 \mathrm{H}), 4.53(\mathrm{~s}, 4 \mathrm{H}), 4.65(\mathrm{~s}, 4 \mathrm{H})$, $4.96(\mathrm{~s}, 8 \mathrm{H}), 6.40(\mathrm{t}, J=2.1 \mathrm{~Hz}, 4 \mathrm{H}), 6.53(\mathrm{t}, J=2.0 \mathrm{~Hz}$, $2 \mathrm{H}), 6.56(\mathrm{~d}, J=2.1 \mathrm{~Hz}, 8 \mathrm{H}), 6.60(\mathrm{~d}, J=2.0 \mathrm{~Hz}, 4 \mathrm{H}), 7.48$ $(\mathrm{s}, 2 \mathrm{H}) ;{ }^{13} \mathrm{C} \mathrm{NMR}\left(75 \mathrm{MHz}, \mathrm{CDCl}_{3}\right) \delta 25.8,29.9,49.9,55.3$, 63.6, 69.9, 72.3, 99.8, 101.4, 105.2, 106.7, 122.3, 139.2, 140.3, 145.1, 159.9, 160.9; MS (FAB): $m / z 1126.5\left[\mathrm{M}^{+}+2 \mathrm{H}\right]$; HRMS (FAB) Calcd for $\mathrm{C}_{62} \mathrm{H}_{72} \mathrm{~N}_{6} \mathrm{O}_{14}$ : 1124.5107. Found: 1125.5172 [ $\left.\mathrm{M}^{+}+\mathrm{H}\right], 1126.5302\left[\mathrm{M}^{+}+2 \mathrm{H}\right]$. PDI: 1.01 .

6-G3. A yellowish oil; 96\% yield; IR 3009, 2940, 2839, 1597, 1458, 1204, 1150, $1049 \mathrm{~cm}^{-1}$; ${ }^{1} \mathrm{H}$ NMR (500 MHz, $\left.\mathrm{CDCl}_{3}\right) \delta 1.31(\mathrm{~m}, 4 \mathrm{H}), 1.84(\mathrm{~m}, 4 \mathrm{H}), 3.78(\mathrm{~s}, 48 \mathrm{H}), 4.26(\mathrm{t}$, $J=7.0 \mathrm{~Hz}, 4 \mathrm{H}), 4.54(\mathrm{~s}, 4 \mathrm{H}), 4.65(\mathrm{~s}, 4 \mathrm{H}), 4.96(\mathrm{~s}, 24 \mathrm{H})$, $6.41(\mathrm{~m}, 8 \mathrm{H}), 6.53(\mathrm{~m}, 2 \mathrm{H}), 6.56(\mathrm{~m}, 4 \mathrm{H}), 6.57(\mathrm{~m}, 16 \mathrm{H})$, $6.61(\mathrm{~m}, 4 \mathrm{H}), 6.68(\mathrm{~m}, 8 \mathrm{H}), 7.47(\mathrm{~s}, 2 \mathrm{H}) ;{ }^{13} \mathrm{C}$ NMR $(75$ $\left.\mathrm{MHz}, \mathrm{CDCl}_{3}\right) \delta 25.7,29.9,49.9$, 55.3, 63.6, 69.9, 70.0,
72.3, 99.9, 101.3, 101.5, 105.2, 106.3, 106.6, 122.3, 139.1, 139.3, 140.3, 145.0, 159.9, 160.0, 160.9; MS (FAB): $\mathrm{m} / z$ $2214.8\left[\mathrm{M}^{+}+2 \mathrm{H}\right]$; HRMS (FAB) Calcd for $\mathrm{C}_{126} \mathrm{H}_{136} \mathrm{~N}_{6} \mathrm{O}_{30}$ : 2212.9301. Found: $2213.9387\left[\mathrm{M}^{+}+\mathrm{H}\right], 2214.9395\left[\mathrm{M}^{+}+\right.$ 2H]. PDI: 1.01 .

6-G4. A yellowish oil; 94\% yield; IR 3009, 2940, 2839, 1597, 1458, 1204, 1150, $1049 \mathrm{~cm}^{-1}$; ${ }^{1} \mathrm{H}$ NMR $(300 \mathrm{MHz}$, $\left.\mathrm{CDCl}_{3}\right) \delta 1.27(\mathrm{~m}, 4 \mathrm{H}), 1.80(\mathrm{~m}, 4 \mathrm{H}), 3.75(\mathrm{~s}, 96 \mathrm{H}), 4.21$ $(\mathrm{m}, 4 \mathrm{H}), 4.51(\mathrm{~s}, 4 \mathrm{H}), 4.63(\mathrm{~s}, 4 \mathrm{H}), 4.94(\mathrm{~s}, 56 \mathrm{H}), 6.39(\mathrm{~m}$, $16 \mathrm{H}), 6.55(\mathrm{~m}, 46 \mathrm{H}), 6.60(\mathrm{~m}, 4 \mathrm{H}), 6.66(\mathrm{~m}, 24 \mathrm{H}), 7.43(\mathrm{~s}$, $2 \mathrm{H}) ;{ }^{13} \mathrm{C} \mathrm{NMR}\left(125 \mathrm{MHz}, \mathrm{CDCl}_{3}\right) \delta 25.8,29.9,49.9,55.3$, $63.7,69.9,70.0,72.3,99.9,101.5,101.6,105.2,106.4$, 106.7, 122.4, 139.1, 139.2, 139.3, 145.0, 159.95, 160.03, 161.0; MS (MALDI): Calcd for $\mathrm{C}_{254} \mathrm{H}_{264} \mathrm{~N}_{6} \mathrm{O}_{62}: 4389.7690$. Found: $4414.7404\left[\mathrm{M}^{+}+\mathrm{Na}+2 \mathrm{H}\right]$. PDI: 1.02 .

\section{Results and Discussion}

The convergent approach to dendrimer synthesis introduced by Fréchet and co-workers revolutionized the synthetic approaches to monodisperse dendrimers. ${ }^{25,26}$ The convergent methodology installs the core in the final step, enabling the incorporation of functionalities. The ability to prepare well-defined symmetrical dendrimers is the most attractive features of the convergent synthesis. The convergent approach allows for a large degree of chemical diversity such that functional groups can be incorporated at nearly central position in the dendritic architecture. The inward growth employed by the convergent synthesis is ideally suited for the synthesis of dendritic-linear-dendritic polymers. We are intrigued to apply this methodology for the synthesis of dendritic-lineardendritic materials as a preliminary investigation. The synthetic strategy for Fréchettype dendrimers, linked by the linear units, utilized a convergent method using the alkyne-functionalized Fréchettype dendrons and the linear di-azides and vice versa (Figure 1). To efficiently connect the alkyne or azide focal point Fréchet-type dendrons with a linear core unit, the synthetic approach selected is based on the click chemistry between an alkyne and an azide in the presence of $\mathrm{Cu}$ (I) species. $^{27}$ The azide focal point Fréchet-type dendrons 1Dm and the alkyne focal point Fréchet-type dendrons 2-Dm ( $m=1 \sim 4$ : generation of dendron) are synthesized according to the reported procedure respectively. ${ }^{21 c, 28,21 \mathrm{e}}$ The 1,7octadiyne $\mathbf{3}$ and 1,6-diazidohexane $\mathbf{4}$ were selected to present alkyne and azide functionalities, available for dendritic polymer growth via click reactions with the dendrons, respectively.

To investigate the effectiveness of the click reaction between the linear di(alkynes) core $\mathbf{3}$ and azide-dendron 1D1 (Scheme I), we have screened with several conditions using various $\mathrm{Cu}(\mathrm{I})$ sources in different solvents. ${ }^{27}$ We have found that the reaction conducted from the condition of $5 \mathrm{~mol} \%$ of $\mathrm{CuSO}_{4} \cdot 5 \mathrm{H}_{2} \mathrm{O}$ with $10 \mathrm{~mol} \%$ of sodium ascorbate 


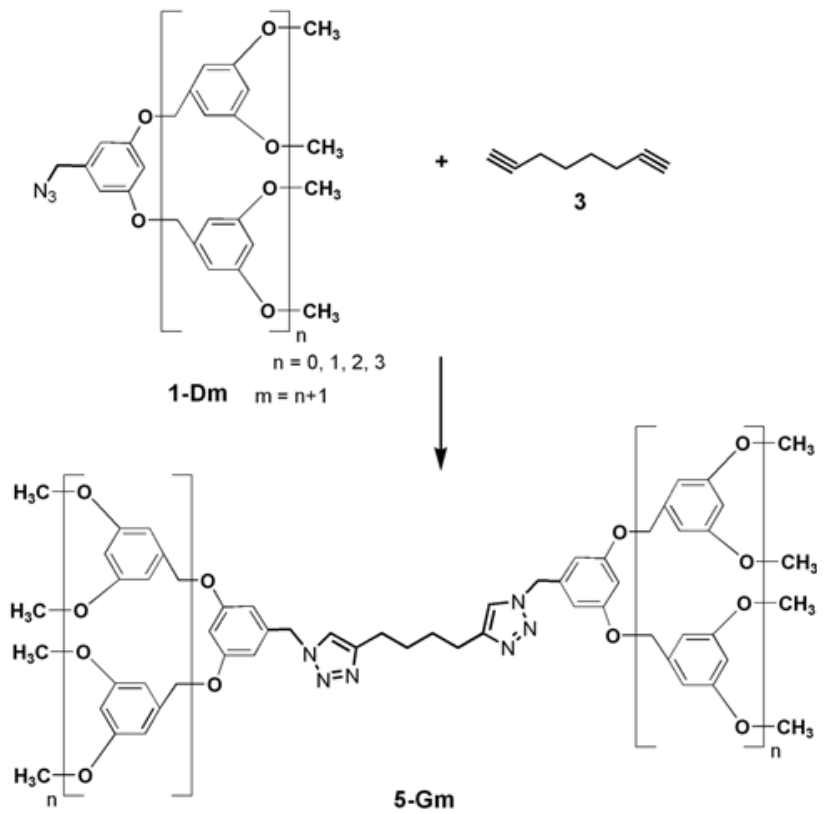

Scheme I. Reagents and conditions: $10 \mathrm{~mol} \%$ of $\mathrm{CuSO}_{4} \cdot 5 \mathrm{H}_{2} \mathrm{O} /$ $20 \mathrm{~mol} \%$ of sodium ascorbate, $\mathrm{DMF} / \mathrm{H}_{2} \mathrm{O}(4: 1), 50{ }^{\circ} \mathrm{C}$.

with respect to the alkyne in a $4: 1$ solvent ratio of DMF to $\mathrm{H}_{2} \mathrm{O}$ for $3.5 \mathrm{~h}$ at $50{ }^{\circ} \mathrm{C}$ provided the desired product 5-G1 in yield of $98 \%$. The disappearance of di(alkynes) 3 as well as generation and disappearance of the mono-triazole derivative were monitored by TLC runs of the reaction mixture. The dendrimer 5-G1 was purified by column chromatography and the structure of dendrimer was confirmed by ${ }^{1} \mathrm{H}$ and ${ }^{13} \mathrm{C}$ NMR spectroscopy, IR spectroscopy, and FAB mass spectra. Given the success in the synthesis of first generation dendrimer, we expanded this reaction to get higher generation dendrimers with $5 \mathrm{~mol} \%$ of $\mathrm{CuSO}_{4} \cdot 5 \mathrm{H}_{2} \mathrm{O}$ with $10 \mathrm{~mol} \%$ of sodium ascorbate with respect to the alkyne in a $4: 1$ solvent ratio of DMF to $\mathrm{H}_{2} \mathrm{O}$. Reactions of the di(alkynes) 3 with 2.2 equiv of 1-D2 and 1-D3 afforded the dendrimers 5-G2 and 5-G3 in yields of 97 and 96\%, respectively, after 5 and $7.5 \mathrm{~h}$, which were separated by column chromatography. In case of 1-D4, the dendritic-linear-dendritic material 5-G4 was obtained in 94\% yield after $18 \mathrm{~h}$. For completion of the reaction between the dendron and the core, the higher generation dendron takes longer time than the lower generation dendron. This observation led us to imagine that the second reaction between the alkyne and the azide was kinetically controlled by the accessibility of acetylide due to the steric bulkiness of dendrons. This comparative efficiency of the click methodology is emphasized by the synthesis of the dendritic-linear-dendritic materials with the tailed made core unit. Therefore this approach may provide new methodological insight into introduction of various linear functional cores and would greatly contribute to researches on the application side. We are now investigat- ing for the linear-dendritic copolymers with the size (length and generation) and the polarity of the blocks.

Structural characterization of the dendrimers 5-Gm with ${ }^{1} \mathrm{H}$ NMR, ${ }^{13} \mathrm{C}$ NMR, and IR spectroscopy showed no defects due to incomplete reaction. From the ${ }^{1} \mathrm{H}$ NMR spectra $\left(\mathrm{CDCl}_{3}\right)$, the peaks of the methylene protons adjacent to the nitrogen of triazole, the triazole proton, and the methylene protons adjacent to the carbon of triazole in dendrimers 5Gm were found at 5.36, 7.19, and $2.68 \mathrm{ppm}$ for 5-G1, 5.36, 7.17, and 2.71 ppm for 5-G2, 5.34, 7.19, and 2.70 ppm for 5-G3, and 5.29, 7.15, and 2.67 ppm for 5-G4, respectively (Figure 2). As the dendrimer generation increased, the peaks of all discussed protons shifted gradually to down-field which may be influenced by the dendritic micro- environment effect. ${ }^{29}$ Analysis of the dendrimers by mass spectrometry as well as by gel-permeation chromatography (GPC) provides no signs of products with defects that would arise from incomplete coupling (Figure 3). As expected, the obtained dendrimer possessed a very well-defined molecu-

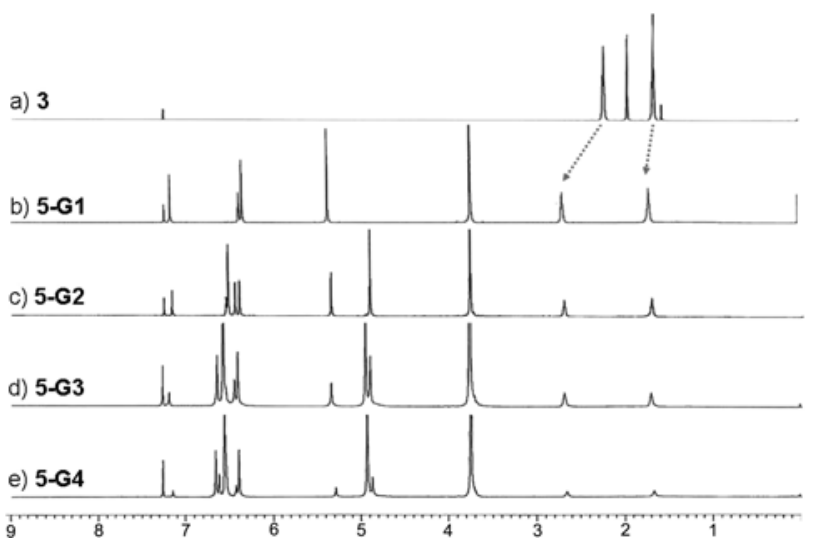

Figure 2. ${ }^{1} \mathrm{HNMR}$ spectra for a) 3, b) 5-G1, c) 5-G2, d) 5-G3, and e) 5-G4 .

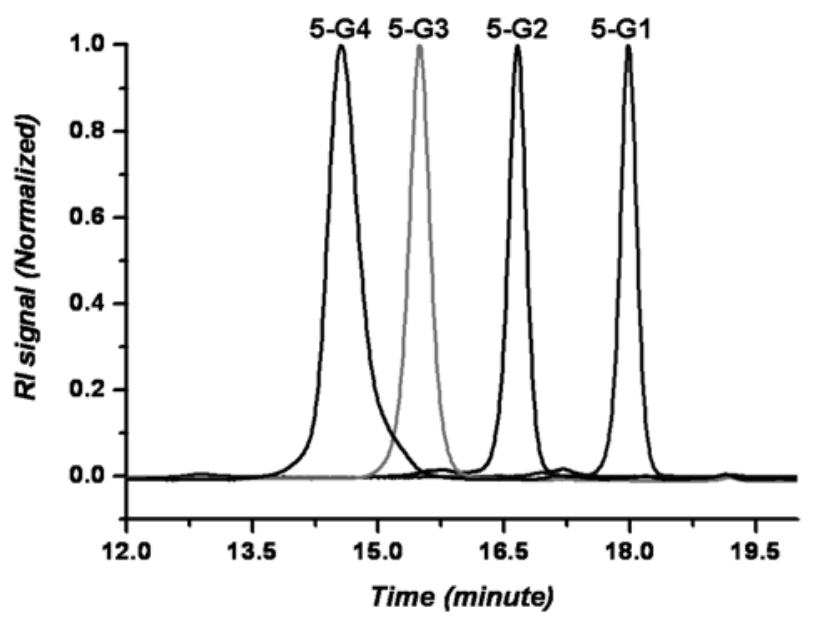

Figure 3. GPC diagrams of dendrimers 5-Gm obtained from THF eluent. 
b) $5-G 3$

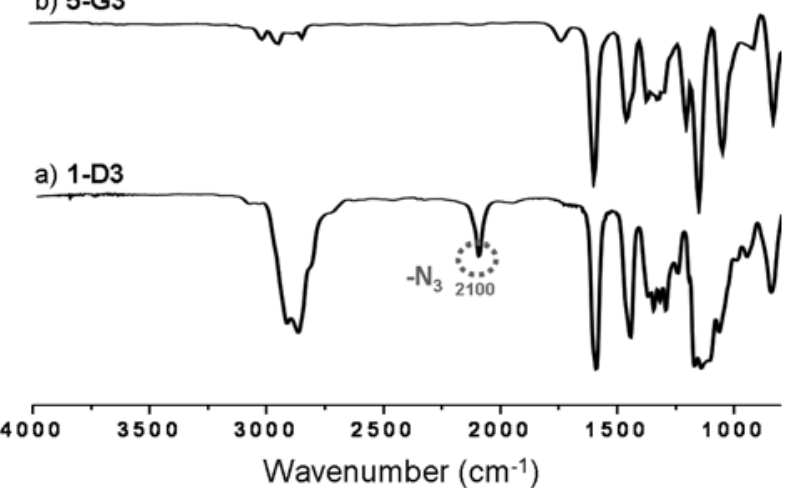

Figure 4. IR spectra for a) 1-D3 and b) 5-G3.

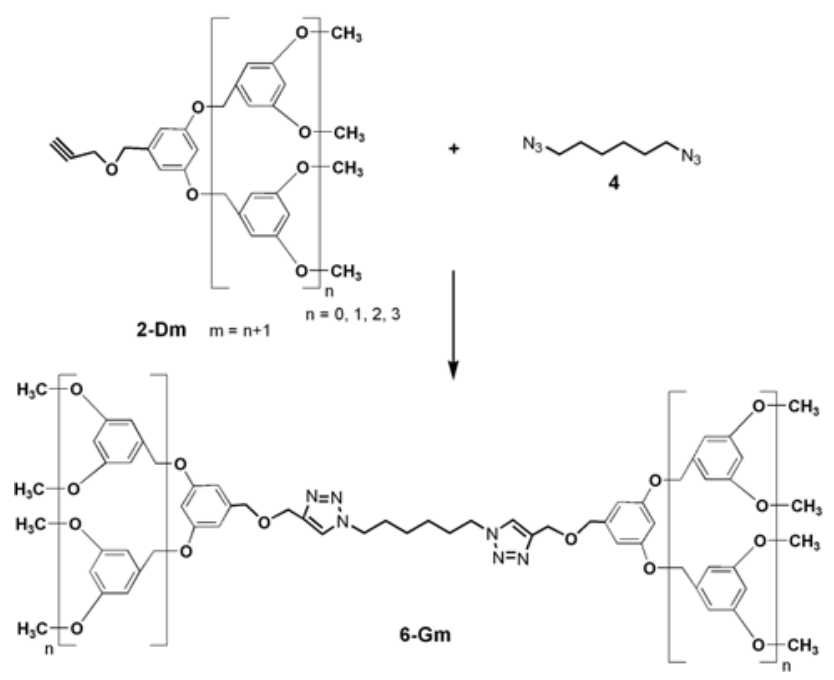

Scheme II. Reagents and conditions: $10 \mathrm{~mol} \%$ of $\mathrm{CuSO}_{4} \cdot 5 \mathrm{H}_{2} \mathrm{O}$ / $20 \mathrm{~mol} \%$ of sodium ascorbate, $\mathrm{DMF} / \mathrm{H}_{2} \mathrm{O}(4: 1), 50{ }^{\circ} \mathrm{C}$.

lar structure with very low polydispersity values $(\mathrm{PDI}=$ 1.01-1.02). The IR spectra shows the disappearance of the acetylene peak at $\sim 3299 \mathrm{~cm}^{-1}$ and the azide peak at $\sim 2100$ $\mathrm{cm}^{-1}$ in the final dendrimer (Figure 4) while the ${ }^{1} \mathrm{H}$ NMR revealed no alkyne peak at around $\delta 1.95 \mathrm{ppm}$ (Figure 2).

Encouraged by this successful proof of concept, we decided to apply this methodology into the synthesis of another dendritic-linear-dendritic materials so that we next turned our attention toward the click reaction between the alkyne-dendrons 2 and 1,6-diazidohexane 4 (Scheme II). Based on optimizations for the synthesis of the Fréchet-type dendrimers with di(alkynes), click reactions for the construction of dendritic polymers 6-Gm were carried out in a $4: 1$ solvent ratio of DMF to $\mathrm{H}_{2} \mathrm{O}$ using $5 \mathrm{~mol}^{2} \mathrm{CuSO}_{4}$. $5 \mathrm{H}_{2} \mathrm{O}$ with $10 \mathrm{~mol} \%$ sodium ascorbate with respect to alkyne. Reaction of the di(azides) 4 and 2.2 equiv of alkynedendron 2-D1, conducted for $0.5 \mathrm{~h}$ at $50{ }^{\circ} \mathrm{C}$, afforded the desired product 6-G1 in yield of $98 \%$. The disappearance of di(azides) $\mathbf{4}$ as well as generation and disappearance of the mono-triazole derivative were also monitored by TLC runs of the reaction mixture. The linear-dendritic copolymer 6G1 was purified by column chromatography and the structure of 6-G1 was confirmed by ${ }^{1} \mathrm{H}$ and ${ }^{13} \mathrm{C}$ NMR spectroscopy, IR spectroscopy, and FAB mass spectra. Given the success in the synthesis of first generation dendrimer, we expanded this reaction to get higher generation dendrimers with $5 \mathrm{~mol} \%$ of $\mathrm{CuSO}_{4} \cdot 5 \mathrm{H}_{2} \mathrm{O}$ with $10 \mathrm{~mol} \%$ of sodium ascorbate with respect to the alkyne in a $4: 1$ solvent ratio of DMF to $\mathrm{H}_{2} \mathrm{O}$. Reactions of the di(azides) 4 with 2.2 equiv of 2-D2 and 2-D3 afforded the dendrimers 6-G2 and 6-G3 in yields of 95 and $96 \%$, respectively, after 1.5 and $2.5 \mathrm{~h}$, which were separated by column chromatography. In case of 2-D4, the dendritic-linear-dendritic material 6-G4 was obtained in $94 \%$ yield after $4.5 \mathrm{~h}$. As the dendron generation increased, the reaction period for stitching of highergeneration dendrons takes longer time than one of the lower-generation dendron which could be caused by the steric hindrance of dendrons. Therefore, the formation of regiospecific 1,4-disubstituted triazoles via copper(I)-catalyzed [2+3]-dipolar cycloaddition reaction between an alkyne and an azide can be regarded as a new and efficient methodology to construct the dendritic-linear-dendritic materials with the tailed made core unit. We are now investigating for the linear-dendritic copolymers with the size (length and generation) and the polarity of the blocks.

The structures of the dendrimers $\mathbf{6 - G m}$ were confirmed by ${ }^{1} \mathrm{H}$ NMR, ${ }^{13} \mathrm{C}$ NMR, and IR spectroscopy. From the ${ }^{1} \mathrm{H}$ NMR spectra $\left(\mathrm{CDCl}_{3}\right)$, the peaks of the methylene protons adjacent to the nitrogen of triazole, the triazole proton, and the methylene protons adjacent to the carbon of triazole in dendrimers 6-Gm were found at $4.32,7.51$, and $4.54 \mathrm{ppm}$ for 6-G1, 4.30, 7.48, and $4.53 \mathrm{ppm}$ for 6-G2, 4.26, 7.47, and $4.54 \mathrm{ppm}$ for 6-G3, and 4.21, 7.43, and $4.51 \mathrm{ppm}$ for $\mathbf{6 - G 4}$, respectively (Figure 5). As the dendrimer generation increased, the peaks of all discussed protons shifted gradually to downfield which may be influenced by the dendritic microenvi-

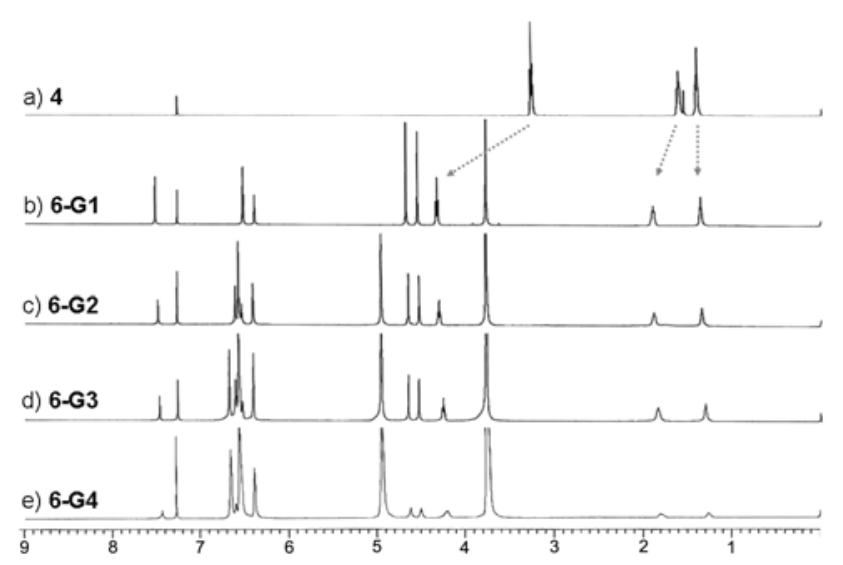

Figure 5. ${ }^{1} \mathrm{H}$ NMR spectra for a) 4, b) 6-G1, c) 6-G2, d) 6-G3, and e) 6-G4. 


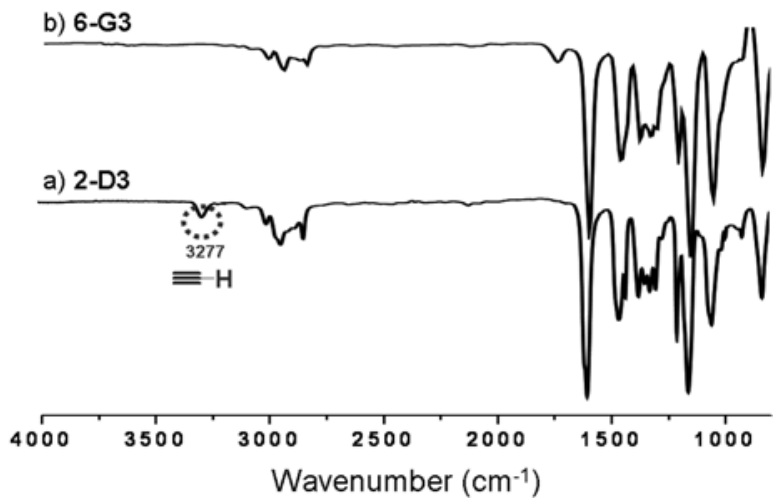

Figure 6. IR spectra for a) 2-D3 and b) 6-G3.

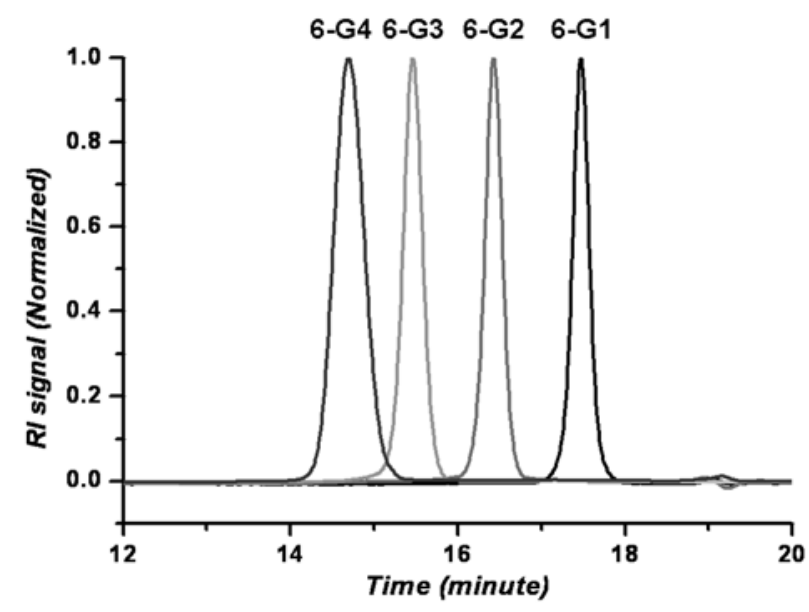

Figure 7. GPC diagrams of dendrimers 6-Gm obtained from THF eluent.

ronment effect. ${ }^{29}$ IR data also confirmed that neither alkyne $\left(\sim 3277 \mathrm{~cm}^{-1}\right)$ nor azide $\left(\sim 2097 \mathrm{~cm}^{-1}\right)$ residues remain in the final dendrimer (Figure 6). Analysis of the dendrimers by mass spectrometry as well as by gel-permeation chromatography (GPC) provides no signs of products with defects that would arise from incomplete coupling (Figure 7). As expected, the obtained dendrimer possessed a very well-defined molecular structure with very low polydispersity values (PDI = 1.01-1.02).

\section{Conclusions}

We have demonstrated general, fast, and efficient stitching methods for the synthesis of Fréchet-type dendrimers with linear units at a core. The stitching method was based on the click chemistry protocol between an alkyne and an azide. The linear building blocks, 1,7-octadiyne and 1,6diazidohexane, were chosen to serve as the core in dendrimer, were stitched together with the azide- and alkynefunctionalized Fréchet-type dendrons in a convergent strategy to lead to the formation of two kinds of Fréchet-type dendrimers with different linear core units, respectively, in high yields. Therefore, the formation of regiospecific 1,4disubstituted triazoles via copper(I)-catalyzed [2+3]-dipolar cycloaddition reaction between an alkyne and an azide can be regarded as a new and efficient methodology to construct the dendritic-linear-dendritic materials with the tailed made core unit. The synthesis and applications of the linear-dendritic copolymers with the size (length and generation) and the polarity of the blocks will now become part of the ongoing research efforts in our laboratories.

Acknowledgement. This research was supported by the Dong-A University Research Fund.

\section{References}

(1) A. C. Grimsdale and K. Müllen, Angew. Chem. Int. Ed., 44, 5592 (2005).

(2) D. A. Tomalia, Prog. Polym. Sci, 30, 294 (2005).

(3) a) G. R. Newkome, C. N. Moorefield, and F. Vögtle, Dendrimers and dendrons: Concepts, synthesis, applications, Wiley-VCH, Weinheim, 2001. b) J. M. J. Fréchet and D. A. Tomalia, Dendrimers and other dendritic polymers, John Wiely \& Sons Ltd., 2002.

(4) a) K. R. Lambrych and I. Gitsov, Macromolecules, 36, 1068 (2003). b) C. M. B. Santini, M. A. Johnson, J. Q. Boedicker, T. A. Hatton, and P. T. Hammond, J. Polym. Sci. Part A: Polym. Chem., 42, 2784 (2004).

(5) E. R. Gillies, T. B. Jonsson, and J. M. J. Fréchet, J. Am. Chem. Soc., 126, 11936 (2004).

(6) I. Gitsov and J. M. J. Fréchet, J. Am. Chem. Soc., 118, 3785 (1996).

(7) a) M. R. Leduc, C. J. Hawker, J. Dao, and J. M. J. Fréchet, J. Am. Chem. Soc., 118, 11111 (1996). b) K. Sill and T. Emrick, J. Polym. Sci. Part A: Polym. Chem., 43, 5429 (2005).

(8) M. R. Leduc, W. Hayes, and J. M. J. Fréchet, J. Polym. Sci. Part A: Polym. Chem., 36, 1 (1998).

(9) I. Gitsov, K. R. Lambrych, V. A. Remnant, and R. Pracitto, J. Polym. Sci. Part A: Polym. Chem., 38, 2711 (2000).

(10) H. Namazi and M. Adeli, J. Polym. Sci. Part A: Polym. Chem., 43, 28 (2005).

(11) I. Gitsov, K. L. Wooley, and J. M. J. Fréchet, Angew. Chem. Int. Ed. Engl., 31, 1200 (1992).

(12) I. Gitsov and J. M. J. Fréchet, Macromolecules, 26, 6536 (1993).

(13) J. C. M. van Hest, M. W. P. Baars, C. Elissen-Román, M. H. P. van Genderen, and E. W. Meijer, Macromolecules, 28, 6689 (1995).

(14) J. C. M. van Hest, D. A. P. Delnoye, M. W. P. L. Baars, C. Elissen-Román, M. H. P. van Genderen, and E. W. Meijer, Chem. Eur. J., 2, 1616 (1996).

(15) T. M. Chapman, G. L. Hillyer, E. J. Mahan, and K. A. Shaffer, J. Am. Chem. Soc., 116, 11195 (1994).

(16) Z. Ge, S. Luo, and S. Liu, J. Polym. Sci. Part A: Polym. Chem., 44, 1357 (2006) and references therein.

(17) I. Gitsov, J. Polym. Sci. Part A: Polym. Chem., 46, 5295 (2008). 
(18) I. Schipor and J. M. J. Fréchet, Polym. Prepr, 35, 480 (1994).

(19) a) V. V. Rostovtsev, L. G. Green, V. V. Fokin, and K. B. Sharpless, Angew. Chem. Int. Ed., 41, 2596 (2002). b) C. W. Tornøe, C. Christensen, and M. Meldal, J. Org. Chem., 67, 3057 (2002).

(20) a) P. Wu, A. K. Feldman, A. K. Nugent, C. J. Hawker, A. Scheel, B. Voit, J. Pyun, J. M. J. Fréchet, K. B. Sharpless, and V. V. Fokin, Angew. Chem. Int. Ed., 43, 3928 (2004). b) M. Malkoch, K. Schleicher, E. Drockenmuller, C. J. Hawker, T. P. Russell, P. Wu, and V. V. Fokin, Macromolecules, 38, 3663 (2005). c) M. J. Joralemon, R. K. O’Reilly, J. B. Matson, A. K. Nugent, C. J. Hawker, and K. L. Wooley, Macromolecules, 38, 5436 (2005).

(21) a) J. W. Lee and B. K. Kim, Bull. Korean Chem. Soc., 26, 658 (2005). b) J. W. Lee, B. K. Kim, and S. H. Jin, Bull. Korean Chem. Soc., 26, 833 (2005). c) J. W. Lee, B. K. Kim, J. H. Kim, W. S. Shin, and S. H. Jin, Bull. Korean Chem. Soc., 26, 1790 (2005). d) J. W. Lee and B. K. Kim, Synthesis, 615 (2006). e) J. W. Lee, J. H. Kim, B. K. Kim, W. S. Shin, and S. H. Jin, Tetrahedron, 62, 894 (2006). f) J. W. Lee, B. K. Kim, H. J. Kim, S. C. Han, W. S. Shin, and S. H. Jin, Macromolecules, 39, 2418 (2006). g) J. W. Lee, J. H. Kim, and B. K. Kim, Tetrahedron Lett., 47, 2683 (2006). h) J. W. Lee, B. K. Kim, J. H. Kim, W. S. Shin, and S. H. Jin, J. Org. Chem., 71, 4988 (2006). i) J. W. Lee, J. H. Kim, B. K. Kim, J. H. Kim, W. S. Shin, and S. H. Jin, Tetrahedron, 62, 9193 (2006). j) J. W. Lee, J. H. Kim, B. K. Kim, J. H. Kim, W. S. Shin, S. H. Jin, and M. Kim, Bull. Korean Chem. Soc., 27, 1795 (2006). k) J. W. Lee, J. H. Kim, H. J. Kim, S. C. Han, J. H. Kim, W. S. Shin, and S. H. Jin, Bioconjugate Chem., 18, 579 (2007). 1) J. W. Lee, H. J. Kim, S. C. Han, J. H. Kim, and S. H. Jin, J. Polym Sci. Part A: Polym. Chem., 46, 1083 (2008).

(22) a) B. Helms, J. L. Mynar, C. J. Hawker, and J. M. J. Fréchet,
J. Am. Chem. Soc., 126, 15020 (2004). b) J. L. Mynar, T.-L. Choi, M. Yoshida, V. Kim, C. J. Hawker, and J. M. J. Fréchet, Chem. Commun., 5169 (2005).

(23) a) C. J. Hawker and K. L. Wooley, Science, 309, 1200 (2005). b) R. K. O'Reilly, M. J. Joralemon, C. J. Hawker, and K. L. Wooley, Chem. Eur. J., 12, 6776 (2006). c) H. Nandivada, H.Y. Chen, L. Bondarenko, and J. Lahann, Angew. Chem. Int. $E d$., 45, 3360 (2006). d) J. E. Moses and A. D. Moorhouse, Chem. Soc. Rev, 36, 1249 (2007).

(24) a) G. Lu, S. Lam, and K. Burgess, Chem. Commun., 1652 (2006). b) B. A. Laurent and S. M. Grayson, J. Am. Chem. Soc., 128, 4238 (2006). c) V. Ladmiral, G. Mantovani, G. J. Clarkson, S. Cauet, J. L. Irwin, and D. M. Haddleton, J. Am. Chem. Soc., 128, 4823 (2006). d) A. P. Vogt and B. S. Sumerlin, Macromolecules, 39, 5286 (2006). e) M. A. Karim, Y.-R. Cho, J. S. Park, S. C. Kim, H. J. Kim, J. W. Lee, Y.-S. Gal, and S. H. Jin, Chem. Commun., 1929 (2008). f) D. Fournier, R. Hoogenboom, and U. S. Schubert, Chem. Soc. Rev., 36, 1369 (2007). g) J.-F. Lutz, Angew. Chem. Int. Ed., 46, 1018 (2007). (h) W. H. Binder and R. Sachsenhofer, Macromol. Rapid Commun., 28, 15 (2007).

(25) C. J. Hawker and J. M. J. Fréchet, J. Am. Chem. Soc., 112, 7638 (1990).

(26) S. M. Grayson and J. M. J. Fréchet, Chem. Rev., 101, 3819 (2001).

(27) a) V. D. Bock, H. Hiemstra, and J. H. van Maarseveen, Eur. J. Org. Chem., 51 (2006). b) M. Meldal and C. W. Tornøe, Chem. Rev., 108, 2952 (2008).

(28) J. W. Lee, S. C. Han, Y.-g. Lee, J. H. Kim, and J. Oh, Bull. Korean Chem. Soc., 29, 1055 (2008).

(29) a) T. K.-K. Mong, A. Niu, H.-F. Chow, C. Wu, L. Li, and R. Chen, Chem. Eur. J., 7, 686 (2001). b) C.-H. Wong, H.-F. Chow, S.-K. Hui, and K.-H. Sze, Org. Lett., 8, 1811 (2006). c) H. Sun and A. E. Kaifer, Org. Lett., 7, 3845 (2005). 